\title{
FILTRASI LIMBAH LAUNDRY DENGAN MEMBRAN ZEOLIT- SILIKA UNTUK MENURUNKAN COD
}

\author{
INFLUENCE OF ADDITION SILICA, VELOCITY OF \\ CENTRIFUGE, AND WASTE WATER CONCENTRATION ON \\ CARACTERISTIC OF ZEOLITE-SILICA MEMBRANE
}

\author{
Anshah Silmi Afifah ${ }^{1)}$ dan Alia Damayanti ${ }^{2)}$ \\ ${ }^{1)} J u r u s a n$ Teknik Lingkungan, Institut Teknologi Sepuluh Nopember, Keputih, \\ Sukolilo, Surabaya, 60111 \\ ${ }^{2)}$ Jurusan Teknik Lingkungan, Institut Teknologi Sepuluh Nopember, Keputih, \\ Sukolilo, Surabaya, 60111 \\ ${ }^{*}$ E-mail:*anshah.silmi@gmail.com
}

\begin{abstract}
Abstrak
Penelitian dilakukan untuk mengetahui variasi membran komposit zeolit-silika terbaik dalam menurunkan kadar COD di dalam limbah laundry. Variasi yang digunakan dalam penelitian adalah penambahan pasir silika dan kecepatan centrifuge pada pembuatan membran serta konsentrasi air limbah pada aplikasi membran. Pengujian membran dalam penelitian dilakukan menggunakan reaktor dengan pola cross flow. Pengujian membran pada limbah laundry dilakukan selama 100 menit dengan waktu pengambilan sampel selama 20 menit. COD dianalisis dengan menggunakan metoda titrimetri refluks tertutup. Untuk mengetahui morfologi dan struktur membran, dilakukan analisa menggunakan alat Scanning Electron Microscopy (SEM). Sedangkan ntuk mengetahui unsur yang ada di dalam membran, dilakukan analisa menggunakan alat Energy Dispersive $X$-ray (EDX).
\end{abstract}

Kata kunci: COD, limbah laundry, membran, silika, zeolit

\begin{abstract}
The study was conducted to determine variations of composite membrane zeolite-silica best in lowering levels of COD in the laundry waste. Variations used in the study is the addition of silica sand and centrifuge speed in making membranes as well as the concentration of waste water on the membrane application. Tests conducted using a membrane in the research reactor with cross flow patterns flow. Testing of the membrane on the laundry waste carried out for 100 minutes with a sampling time for 20 minutes. COD analyzed using closed reflux titrimetric method. To determine the morphology and structure of the membrane, analysis using a Scanning Electron Microscopy (SEM). To determine the elements present in the membrane, analysis using tools Energy Dispersive X-ray (EDX).
\end{abstract}

Keyword: COD, laundry waste, membrane, silica, zeolite 


\section{PENDAHULUAN}

Salah satu penyebab pencemaran badan air permukaan dan air tanah yaitu adanya effluent dari air limbah domestik yang kualitasnya masih kurang baik. Hal ini dibuktikan dari hasil uji laboratorium beberapa parameter di sungai Surabaya yang melebihi baku mutu sesuai kelasnya. Sebagian besar pengolahan limbah cair hanya difokuskan pada limbah yang berasal dari kegiatan industri, sedangkan berdasarkan kajian yang dilakukan oleh Perum Jasa Tirta awal tahun 2000 di Kali Mas di Surabaya, disebutkan bahwa sumber pencemaran terbesar berasal dari limbah cair domestik yang memberikan kontribusi sebesar $87 \%$ dan sisanya sebesar $13 \%$ berasal dari limbah cair industri.

Limbah laundry dapat dikategorikan sebagai sumber limbah cair domestik yang dapat mencemari badan air permukaan dan air tanah. Jasa pencucian pakaian atau laundry pada saat ini berkembang dimana-mana terutama di daerah pemukiman. Sebagian besar usaha laundry tersebut tidak memiliki instalasi pengolahan air limbah. Air limbah yang dihasilkan langsung disalurkan ke saluran drainase yang pada akhirnya akan mengalir ke badan air.

Limbah laundry banyak menggunakan deterjen sebagai bahan pencuci. Penggunaan deterjen semakin meningkat dikarenakan deterjen mempunyai sifat-sifat pembersih yang efektif dibandingkan dengan sabun biasa. Pada tahun 1998 jumlah deterjen yang diproduksi diseluruh dunia sekitar $21,5 \times 10^{6}$ ton. Pemakaian deterjen yang makin meningkat dapat menimbulkan permasalahan berupa penyebaran pencemar ke lingkungan terutama badan air permukaan.

Beberapa studi literatur diketahui limbah laundry mengandung nilai Biological Oxygen Demand (BOD5) sebesar 53 - $267 \mathrm{mg} / \mathrm{L}$, Chemical Oxygen Demand (COD) sebesar 320 - 1040 $\mathrm{mg} / \mathrm{L}$, fosfat sebesar $0,35-1,34 \mathrm{mg} / \mathrm{L}$ (Umaya dan Karnaningroem, 2013), Total Suspended Solid (TSS) sebesar 435 - $442 \mathrm{mg} / \mathrm{L}$ (Setyobudiarso dan Yuwono, 2014), MBAS (Detergent) sebesar 16,13 $\mathrm{mg} / \mathrm{L}$ dan $\mathrm{pH}=7$ (Rachmawati, dkk., 2014). Kondisi parameter tersebut secara umum tidak memenuhi baku mutu yang ditetapkan pada Peraturan Gubernur Jawa Timur Nomor 2013 tentang Baku Mutu Air Limbah Bagi Industri dan/atau Kegiatan Usaha Lainnya. Parameter yang tidak memenuhi diantaranya $\mathrm{BOD}_{5}$, COD, TSS, dan MBAS (Detergent)

Apabila kadar COD tinggi dalam air limbah maka organisme anaerob semakin aktif memecah atau mengoksidasi bahan-bahan organik yang terdapat dalam air limbah, akibatnya bakteri aerob akan mati karena kekurangan oksigen dan sebaliknya organisme anaerob lebih dominan sehingga air berbau busuk, kehidupan biota air terganggu, menimbulkan gangguan estetika, dan dapat menimbulkan spesies penyebab penyakit.

Berbagai metode untuk mengatasi masalah pencemaran yang berasal dari limbah cair terus dikembangkan. Metode yang sering diterapkan untuk pengolahan limbah cair biasanya memerlukan lahan yang luas dan pengoperasian yang sulit (Maharani dan Damayanti, 2013), namun demikian metode-metode ini belum mampu mencapai standar batas minimum yang telah ditetapkan sehingga memerlukan proses pengolahan lebih lanjut. Untuk itu diperlukan suatu teknologi yang lebih mudah diaplikasikan dalam pengolahan limbah cair, salah satunya adalah penggunaan teknologi membran (Maharani dan Damayanti, 2013).

Teknologi membran memiliki kelebihan dan kekurangan jika dibandingkan dengan teknologi pengolahan lain. Keuntungan tekonologi membran antara lain energi yang dibutuhkan rendah, tidak memerlukan tambahan bahan kimia, tidak menghasilkan kontaminan maupun polutan, memerlukan lahan yang relatif kecil dan bersifat modular sehingga mudah dikombinasikan dengan produk teknologi lain. Sedangkan kekurangannya adalah penggunaannya dalam menangani limbah masih relatif mahal, karena membran dan modul membran masih impor. Untuk itu diperlukan pembuatan teknologi membran yang dibuat dari bahan baku yang murah, mudah didapat, dan stabil pada suhu tinggi (Maharani dan Damayanti, 2013). Penelitian yang dilakukan 
menyatakan bahwa pengolahan limbah laundry volume $20 \mathrm{~m}^{3}$ menggunakan teknologi membran akan menyebabkan permeabilitas membran menurun hingga $25 \%$. Hal ini dikarenakan adanya fouling membran yang disebabkan adsorpsi surfaktan sisa limbah ke dalam membran. Fouling membran merupakan perubahan irreversibel yang terjadi pada membran yang disebabkan oleh interaksi fisik dan atau kimia spesifik antara membran dan komponen-komponen yang ada dalam aliran proses. Faktor lain yang menyebabkan fouling membran yaitu aliran umpan yang digunakan sistem dead end. Lapisan fouling membran (foulant) ini menghambat filtrasi. Foulant akan terakumulasi pada permukaan membran karena tidak ikut ambil bagian dalam transfer massa. Akibatnya foulant akan mengurangi efektivitas dan fluks membran.

Proses filtrasi laminar (dead end), aliran umpan tegak lurus ke permukaan membran, sehingga partikel-partikel terakumulasi dan membentuk suatu lapisan pada permukaan membran yang akan menyebabkan menurunnya fluks membran (Nasir dkk., 2012).

Dalam penelitian digunakan teknologi membran dengan pola crossflow. Permeat yang dihasikan dari pola crossflow filtration tidak sebesar yang dihasilkan pada dead end, namun kelebihan pola crossflow yaitu aliran dapat membantu menyingkirkan cake filter yang menghalangi media filter selama proses filtrasi sehingga meningkatkan jangka waktu penggunaan suatu media filter. Crossflow filtration dapat digunakan untuk proses kontinyu, tidak seperti dead end filtration yang cenderung bersifat batch. Crossflow filtration dapat beroperasi terus-menerus pada beban padatan yang relatif tinggi dengan meminimalisasi risiko terjadinya penyumbatan. Cross flow digunakan untuk mengurangi penumpukan material pada membran dengan cara menyapu material dari permukaan sehingga dapat memperlambat terjadinya fouling dini (Pusparini dan Isyuniarto, 2010).

Membran zeolit memiliki kelebihan, karena kelimpahan zeolit di alam cukup besar, zeolit alam memiliki sifat tidak mudah mengembang dalam air dan mudah membentuk suspensi untuk melapisi membran sebagai pendukung. Komposit polimer dewasa ini semakin berkembang, bersaing dengan komposit logam maupun keramik. Berbagai pemrosesan komposit terus dipacu, diarahkan ke sasaran produk yang bersifat seperti yang dikehendaki. Pembuatan komposit polimer dilakukan dengan memadukan dua material yang berbeda sehingga dapat meningkatkan sifat mekanik dari material tersebut (Barleany dkk, 2011). Permasalahan yang sering timbul dalam pembuatan produk komposit polimer yakni sifat fisiknya berkurang akibat temperatur yang tinggi sehingga pemakaian bahan tidak dapat tahan lama, untuk memperbaiki sifat fisik tersebut diperlukan pemilihan jenis polimer yang tepat, dan untuk menunjang sifat termalnya diperlukan pengisi (filler). Jika suatu polimer dikompositkan dengan suatu silikat, maka material ini akan menunjukan peningkatan yang sangat baik pada sifat-sifat seperti mekanik dan termal yang melebihi sifat polimer murninya (Rosyadi, dkk., 2010). Pasir silika bersifat stabil, kelimpahan di alam cukup besar, dan relatif murah (Maharani dan Damayanti, 2013). Oleh sebab itu, dalam penelitian perlu dikaji mengenai efisiensi membran sintesis dari bahan dasar zeolit yang dikompositkan dengan variasi penambahan silika dalam menurunkan kadar COD yang terkandung dalam limbah laundry.

\section{METODA}

Penelitian dilakukan untuk menentukan variasi penambahan silika dan kecepatan centrifuge terbaik untuk pembuatan membran zeolit-silika serta menentukan konsentrasi air limbah terbaik dalam pengaplikasian membran zeolit-silika dalam menurunkan kadar COD limbah laundry.

\section{Alat dan bahan}

Alat dan bahan yang digunakan dalam tahap penyiapan zeolit-silika diantaranya: alat tumbuk zeolit-silika (ball mill), saringan 200 mesh, oven, spatula logam dan kaca, mortar, gelas beaker, zeolit dan silika, larutan $\mathrm{HCl}$ dan aquades. 
Alat dan bahan yang digunakan dalam tahap pembuatan larutan membran adalah: neraca analitik, centrifuge, magnetic stirer, spatula logam dan kaca, gelas beaker, 2-Propanol, $\mathrm{NH}_{4} \mathrm{Cl}$ yang telah dilarutkan dalam aquades, zeolit dan silika yang terbentuk dari tahap penyiapan.

Alat dan bahan yang digunakan dalam tahap pencetakan membran adalah: water batch, magnetic stirer beserta kompor listrik, spatula, cawan petri ukuran $4 \mathrm{~cm}$, sendok, PVA (Poly Vinil Alcohol) PEG (Poly Etilen Glicol), zeolit dan silika yang terbentuk dari tahap pembuatan larutan membran.

\section{Penyiapan Zeolit-Silika}

Langkah - langkah yang dilakukan dalam tahap penyiapan zeolit-silika diantaranya: Zeolit dan silika masing-masing ditumbuk dan diayak dengan ayakan 200 mesh, zeolit dan silika masing-masing diletakkan dalam gelas beaker dan dicuci dengan cara direndam menggunakan larutan $\mathrm{HCl}$ selama 12 jam untuk menghilangkan zat pengotornya.

Dalam literatur diketahui pengaktifan mineral lokal (zeolit dan silika) dapat dilakukan dengan cara pemanasan atau dengan menambahkan larutan asam atau garam (sulfat, khlorida, nitrat). Langkah ini bertujuan untuk membersihkan permukaan pori-pori, membuang senyawasenyawa pengotor dan pada akhirnya terjadi reposisi letak atom yang dapat dipertukarkan (Susetyaningsih, dkk., 2010). $\mathrm{HCl}$ dipisahkan dari zeolit dan silika, masing - masing dicuci dengan aquades. Aquades dipisahkan dari zeolit dan silika, masing - masing dioven selama 24 jam. Zeolit dan silika setelah dioven akan kering dan setelah itu dapat ditumbuk dengan mortar untuk menghindari terjadinya penggumpalan. Zeolit dan silika siap digunakan untuk tahap pembuatan larutan membran.

\section{Pembuatan Larutan Membran}

Langkah - langkah yang dilakukan dalam pembuatan larutan membran di antaranya: Menimbang serbuk zeolit dan silika yang dihasilkan dari tahap penyiapan zeolit dan silika menggunakan neraca analitik dengan variasi komposisi penambahan silika sebesar $0,5 \%$, $1,5 \%$, dan $3 \%$ berat zeolit. Zeolit-silika dimasukkan ke dalam botol centrifuge kemudian ditambahkan 2-Propanol. Campuran tersebut dicentrifuge selama 20 menit dengan variasi kecepatan yaitu 200 dan $600 \mathrm{rpm}$. Cairan di atas supernatan dipisahkan. Endapan zeolit-silika dimasukkan ke gelas beaker yang telah berisi campuran $\mathrm{NH}_{4} \mathrm{Cl}$ dan aquades. Larutan zeolitsilika diaduk dengan magnetic stirer selama \pm 1 jam. Campuran larutan berupa $\mathrm{NH}_{4} \mathrm{Cl}$ dan aquades dipisahkan dari zeolit dan silika. Zeolitsilika siap digunakan untuk tahap pencetakan membran.

\section{Pencetakan Membran}

PVA dilarutkan dalam aquades menggunakan water batch pada suhu $95^{\circ} \mathrm{C}$ dan kecepatan maksimum, dengan perbandingan massa:volume sebesar 1:10, Zeolit-Silika dari tahap pembuatan larutan membran dimasukkan dalam gelas beaker dan diletakkan dalam kompor yang juga zebagai magnetic stirer. Pemanasan dilakukan dalam suhu $180^{\circ} \mathrm{C}$ dan pengadukan dilakukan dalam kecepatan $650 \mathrm{rpm}$. PVA dan PEG dengan perbandingan 3:1 dituang dalam gelas beaker secara bersamaan, dan selanjutnya ditunggu hingga zeolit-silika mengental. Menurut penelitian Aprilia et al. (2012), bahan pendukung campuran PVA (Poly Vinil Alcohol) dan PEG (Poly Etilen Glicol) dengan menggunakan variasi yang tepat dapat membentuk susunan pori-pori yang bagus. Fungsi PVA adalah sebagai zat perekat bagi kristal-kristal dari silika agar menyatu dan membentuk suatu ikatan sehingga dihasilkan suatu membran padat. Penambahan PEG dapat meningkatkan keteraturan bentuk pori-pori pada membran padat silika. Zeolit-silika yang sudah mengental dapat dicetak pada cawan petri dengan sendok yang disiapkan, sehingga didapatkan ketebalan yang sama antar membran $\pm 1 \mathrm{~mm}$.

\section{Pemilihan Pompa}

Pompa yang digunakan untuk pengujian membran pada reaktor cross flow yaitu pompa 
sentrifugal jenis pompa booster. Pompa booster digunakan untuk meningkatkan tekanan sehingga cukup kuat untuk mendorong air melewati membran. Pemilihan pompa yang sesuai dengan tekanan yang diperlukan sangat penting agar operasi membran dapat berjalan.

Spesifikasi pompa:

$\begin{array}{ll}\text { Jenis pompa } & : \text { Booster pump } \\ \text { Voltase } & : 220-240 \text { Volt } \\ \text { Ampere } & : 0,22 \text { amper.detik } \\ \text { Debit } & : 0,31 \text { gpm }\end{array}$

\section{Pengujian Membran}

1. Membran hasil dari tahap pencetakan membran diletakkan di dalam reaktor cross flow. Membran diletakkan di dalam reaktor pada tempat peletakan membran dan dipastikan dalam keadaan tertutup rapat agar tidak terjadi kebocoran.

2. Air limbah ditampung dan dipompa menuju reaktor membran, dengan variasi sebagai berikut:

- Air limbah 50\%, variasi air limbah dilakukan pencampuran dengan air PDAM 50\%.

- Air limbah $100 \%$, variasi air limbah tidak dilakukan pencampuran dengan air PDAM.

3. Pompa dinyalakan dan dilakukan pengaturan tekanan 2-3 bar.

4. Setelah mencapai tekanan yang diinginkan, dilakukan uji permeabilitas salah satu variasi membran dan selanjutnya dilakukan running dengan limbah laundry. Air limbah yang melewati membran yaitu permeat ditampung pada wadah untuk selanjutnya dapat dianalisis COD.

5. Retentate/aliran yang tidak dapat melewati membran dialirkan kembali ke bak penampung air limbah.

Reaktor cross flow terdiri atas manometer, valve, water mur, dan selang. Manometer berfungsi untuk menunjukkan tekanan di dalam reaktor. Water mur digunakan untuk menutup rapat membran dalam reaktor agar tidak bocor. Pada reaktor dipasang by pass untuk mengatur tekanan dan aliran air retentate ke bak penampung air limbah awal. Selang digunakan untuk mengalirkan air menuju ke bak penampung awal. Rangkaian reaktor dan desain reaktor cross flow dapat dilihat pada Gambar 1.

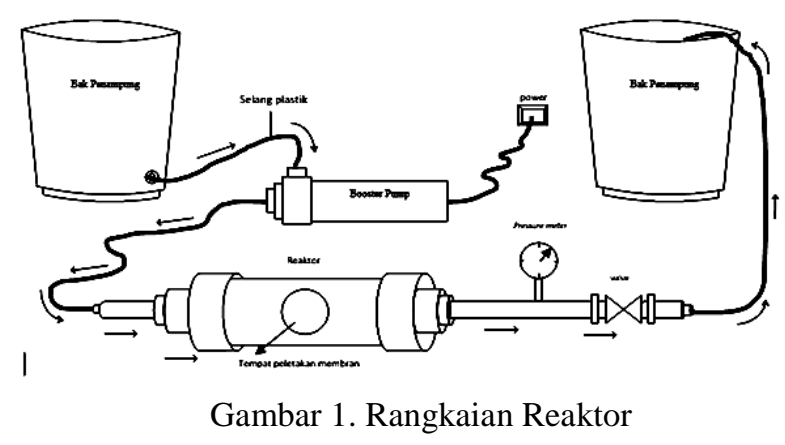

\section{HASIL DAN PEMBAHASAN}

\section{Uji Permeabilitas}

Uji permeabilitas salah satu variasi membran digunakan untuk mengetahui membran termasuk dalam kategori mikrofiltrasi, ultrafiltrasi, atau nanofiltrasi Uji permeabilitas dilakukan dengan cara meletakkan membran seluas $0,001256 \mathrm{~m}^{2}$ pada reaktor. Air aquades di masukkan dalam ember penampung yang terhubung dengan reaktor. Pompa dinyalakan dan valve yang semula dalam keaadaan terbuka ditutup secara perlahan untuk memperbesar tekanan hingga didapatkan tekanan yang sesuai yaitu $2-3$ Bar, setelah mencapai tekanan yang diinginkan air aquades yang melewati membran yaitu permeate ditampung pada wadah dan dihitung volumenya. Volume yang tertampung selanjutnya digunakan untuk menghitung nilai fluks. Fluks merupakan parameter terpenting kelayakan penerapan proses membran, karena fluks menentukan kebutuhan luas membran. Fluks umumnya tinggi pada awal operasi dan menurun dengan meningkatnya waktu operasi dan setelah waktu tertentu fluks mencapai kondisi tunak, dimana fluks tidak mengalami perubahan secara berarti dengan meningkatnya waktu operasi. Nilai fluks pada kondisi ini selain dipengaruhi oleh jenis membran, juga dipengaruhi oleh kondisi operasi seperti kecepatan aliran umpan, tekanan 
transmembrane, konsentrasi padatan, dan temperatur. Fluks yang diperoleh dari hasil pengujian membran dengan mengalirkan air aquades yaitu 99,7 L/m² jam.

Uji permeabilitas membran digunakan untuk mengetahui membran termasuk dalam kategori mikrofiltrasi, ultrafiltrasi, atau nanofiltrasi. Permeabilitas membran dapat dihitung dari nilai fluks yang didapat dan kemudian membaginya dengan tekanan yang digunakan. Tekanan pompa yang digunakan saat pengujian membran yaitu 2 bar, sehingga permeabilitas membran zeolitsilika dapat disimpulkan termasuk dalam kategori membran ultrafiltasi karena memiliki permeabilitas membran sebesar $49,85 \mathrm{~L} / \mathrm{m}^{2}$ jam.bar. Karakteristik struktur membran ultrafiltrasi beroperasi pada tekanan antara 1-5 bar dan batasan permeabilitasnya adalah 10-50 L/m2.jam.bar.

\section{Uji Membran dengan Limbah Laundry}

\section{Pengujian Nilai Fluks}

Nilai fluks menunjukkan semakin lama waktu pengujian pada reaktor, nilai fluks akan semakin menurun. Perubahan nilai fluks ini disebabkan karena laju pembentukan cake yang berbeda tiap menit. Pada menit 20-40, terjadi penurunan nilai fluks yang cukup signifikan karena pada menit awal membran masih bersih sehingga laju pembentukan cake masih kecil.

Berdasarkan penelitian Aufiyah dan Damayanti (2013), nilai fluks akan cenderung menurun seiring dengan bertambahnya waktu. Penurunan nilai fluks ini dapat disebabkan terjadinya fouling pada membran. Fouling membran merupakan perubahan irreversibel yang terjadi pada membran yang disebabkan oleh interaksi fisik dan atau kimia spesifik antara membran dan komponen-komponen yang ada dalam aliran proses. Lapisan fouling membran (foulant) ini menghambat filtrasi. Foulant akan terakumulasi pada permukaan membran karena tidak ikut ambil bagian dalam transfer massa. Akibatnya foulant akan mengurangi efektivitas dan fluks membran. Nilai fluks tertinggi pada variasi konsentrasi air limbah 50\% yaitu sebesar 80,61
$\mathrm{L} / \mathrm{m}^{2}$.jam dan pada konsentrasi air limbah $100 \%$ sebesar 34,47 L/m².jam.

Untuk menyimpulkan hasil dilakukan uji statistika menggunakan program IBM SPSS 20 untuk mengetahui pengaruh variasi penambahan silika, variasi kecepatan centrifuge, variasi konsentrasi air limbah, dan waktu pengambilan permeat terhadap penurunan fluks. Hasil uji statistika dijelaskan bahwa level faktor yang menghasilkan nilai penurunan fluks tertinggi yaitu pada variasi penambahan silika $1,5 \%$, kecepatan centrifuge $600 \mathrm{rpm}$, konsentrasi air limbah $50 \%$, dan waktu operasi pada menit ke $20-40$.

Variasi penambahan silika $1,5 \%$ dan kecepatan centrifuge $600 \mathrm{rpm}$ memberikan nilai penurunan fluks tertinggi pada menit-menit awal pengambilan sampel (menit ke 20-40-60), kondisi ini berbanding lurus dengan \% rejeksi yang dihasilkan. Penurunan nilai fluks yang cukup tinggi pada menit-menit awal pengambilan sampel (menit ke 20-40-60) mengindikasikan terbentuknya cake atau lapisan padatan yang tidak dapat tersaring oleh membran menjadi lebih tebal. Penebalan cake pada membran menyebabkan pori membran semakin tertutup, hal ini mengakibat \% rejeksi membran terhadap polutan menjadi lebih tinggi.

Aplikasi membran pada variasi konsentasi air limbah yang paling optimum dalam menghasilkan nilai fluks adalah membran yang digunakan untuk variasi konsentrasi air limbah $50 \%$. Hal ini terjadi karena konsentrasi air limbah $50 \%$ memiliki partikel yang lebih kecil dari konsentrasi air limbah $100 \%$, sehingga menyebabkan fouling pada membran menjadi lebih lambat dan nilai fluks yang dihasilkan menjadi lebih besar.

\section{Pengujian Nilai Rejeksi Membran}

Nilai COD dapat dianalisis menggunakan metode titimetri refluks tertutup. Nilai rejeksi COD tertinggi pada variasi penambahan silika $0,5 \%$ sebesar $91,02 \%, 1,5 \%$ sebesar $91,26 \%$, dan $3 \%$ sebesar $78,08 \%$. Variasi penambahan berat silika diketahui kondisi membran yang 
paling optimum dalam menghasilkan nilai rejeksi COD adalah membran dengan variasi penambahan silika $1,5 \%$. Penambahan silika sebesar $1,5 \%$ memiliki nilai rejeksi yang cenderung lebih besar dibanding penambahan silika sebesar $0,5 \%$.

Berdasarkan Susetyaningsing, dkk (2010), penambahan pasir silika dapat meningkatkan daya sorpsi pada membran karena dapat mencegah terjadinya gumpalan pada pasir zeolit, namun demikian tidak berlaku pada penambahan silika $3 \%$. Nilai rejeksi pada variasi penambahan silika $3 \%$ lebih kecil jika dibandingkan dengan $1,5 \%$ dan $0,5 \%$. Penambahan silika sebesar $3 \%$ dapat membuat membran memilika sifat hidrofobik menjelaskan, zeolit dengan kandungan silika tinggi sifatnya akan menjadi hidrofobik. Sifat hidrofobik pada zeolit menyebabkan daya sorpsi zeolit terhadap air dan molekul polar lain berkurang.

Nilai rejeksi tertinggi COD pada variasi kecepatan centrifuge $200 \mathrm{rpm}$ sebesar $86,85 \%$, $600 \mathrm{rpm}$ sebesar 91,26\%, Variasi kecepatan centrifuge diketahui kondisi membran yang paling optimum dalam meningkatkan nilai rejeksi COD adalah membran dengan variasi kecepatan centrifuge $600 \mathrm{rpm}$. Hal ini disebabkan karena semakin besar kecepatan centrifuge akan menyebabkan pencampuran silika ke dalam zeolit semakin sempurna. Semakin tinggi kecepatan centrifuge, semakin baik proses pencampuran silika kedalam zeolit (Lin, dkk., 2013).

Berdasarkan penelitian yang dilakukan oleh Citra dan Damayanti (2012), kecepatan centrifuge optimum yang digunakan untuk pembuatan membran yaitu $600 \mathrm{rpm}$.

Nilai rejeksi tertinggi COD pada variasi konsentrasi air limbah $50 \%$ sebesar $86,7 \%$, pada konsentrasi air limbah $100 \%$ sebesar 91,26\%. Variasi konsentrasi limbah pada diketahui kondisi membran yang paling optimum dalam menghasilkan nilai rejeksi COD adalah membran yang digunakan untuk variasi konsentrasi air limbah $100 \%$. Hal ini terjadi karena konsentrasi air limbah $100 \%$ memiliki partikel yang lebih besar dari konsentrasi air limbah $50 \%$, yang menyebabkan pembentukan cake pada membran berlangsung lebih cepat. Proses pembentukan cake pada membran menyebabkan pori pada membran semakin kecil, sehingga lebih efektif dalam meningkatkan nilai rejeksi COD.

\section{Analisa Scanning Electron Microscopy (SEM)}

Scanning Electron Microscopy (SEM) merupakan sebuah tipe mikroskop elektron yang menggambarkan permukaan sampel melalui proses scan dengan menggunakan pancaran energi yang tinggi dari elektron dalam suatu pola scan raster. SEM digunakan untuk mengamati morfologi suatu bahan dengan prinsip kerja sifat gelombang dari elektron yaitu difraksi pada sudut yang sangat kecil. Penggunakan SEM sebagai salah satu mikroskop elektron didasarkan pada fakta bahwa alat ini dapat digunakan untuk mengamati dan mengkarakterisasi bahan dengan skala mikrometer $(\mu \mathrm{m})$ hingga nanometer $(\mathrm{nm})$. Analisa SEM digunakan untuk mengamati morfologi membran zeolit-silika sebelum dan sesudah digunakan running. Hasil analisa SEM dapat dilihat pada Gambar 2 dan Gambar 3.

Gambar 2 (a) menunjukkan struktur morfologi membran tampak atas sebelum digunakan running. Membran memiliki struktur asimetris yang terdiri dari lapisan tipis yang aktif dan beberapa lapisan pendukung yang berpori di bawahnya (heterogen). Ukuran dan kerapatan porinya tidak sama dari bagian atas ke bawah. Hasil SEM Gambar 2 (a) diketahui ukuran pori yang dapat teridentifikasi $\pm 1-5 \mu \mathrm{m}$.

Gambar 2 (b) menunjukkan struktur morfologi membran tampak atas setelah digunakan running. Diameter pori membran setelah digunakan running cenderung lebih kecil jika dibandingkan dengan diameter pori membran sebelum digunakan running. Hasil SEM Gambar 2 (a) diketahui ukuran pori yang dapat teridentifikasi $\pm 0,5-2 \mu \mathrm{m}$. Ukuran pori membran yang lebih kecil ini disebabkan karena adanya penyumbatan dari foulant atau partikel padatan yang tidak dapat tersaring oleh membran. Berdasarkan penelitian Rachmawati 
dan Damayanti (2013), terjadinya penyumbatan pori-pori pada membran karena penumpukan material tidak hanya terjadi di permukaan atas atau lapisan luar membran saja, akan tetapi dimungkinkan juga dibagian dalam membran.
Pengotor yang masuk ke dalam lapisan dalam tersebut terjadi akibat adanya tekanan yang diberikan selama operasi membran. Tekanan akan mendorong deposisi partikel pada permukaan membran.

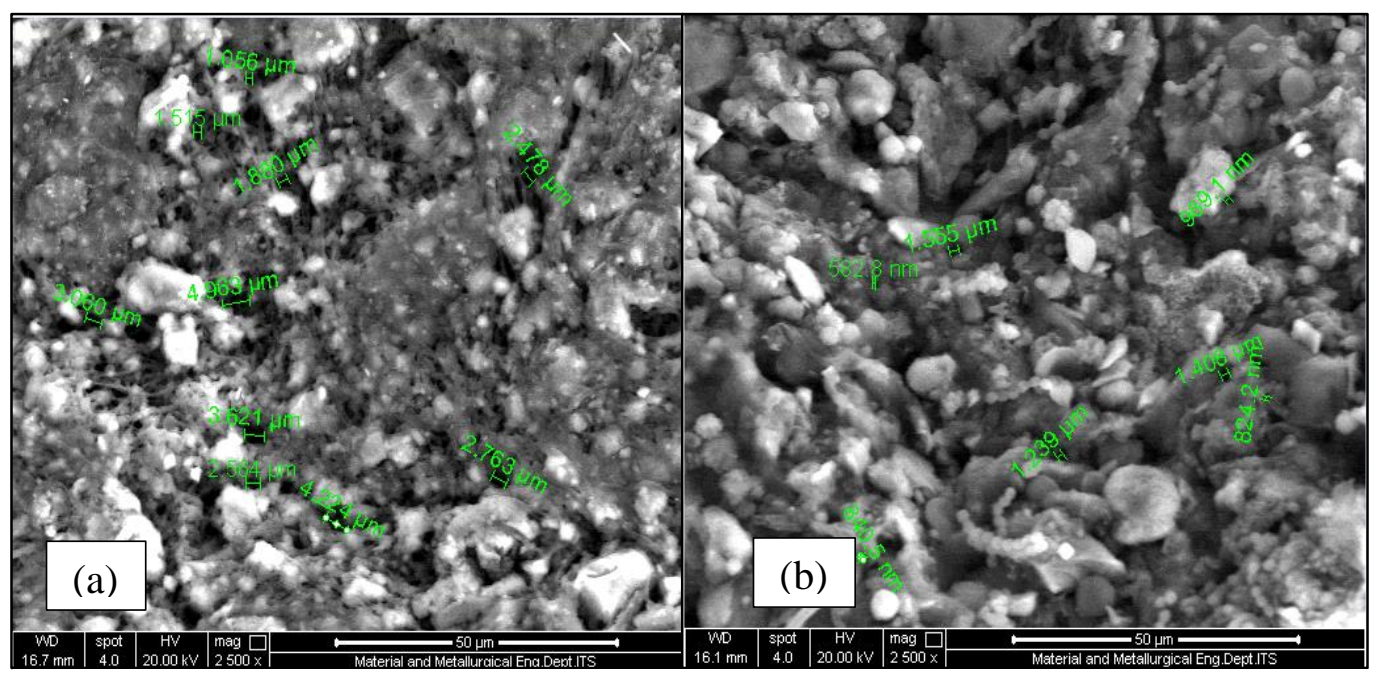

Gambar 2. Hasil Foto SEM tampak Atas (a) Awal (b) Akhir

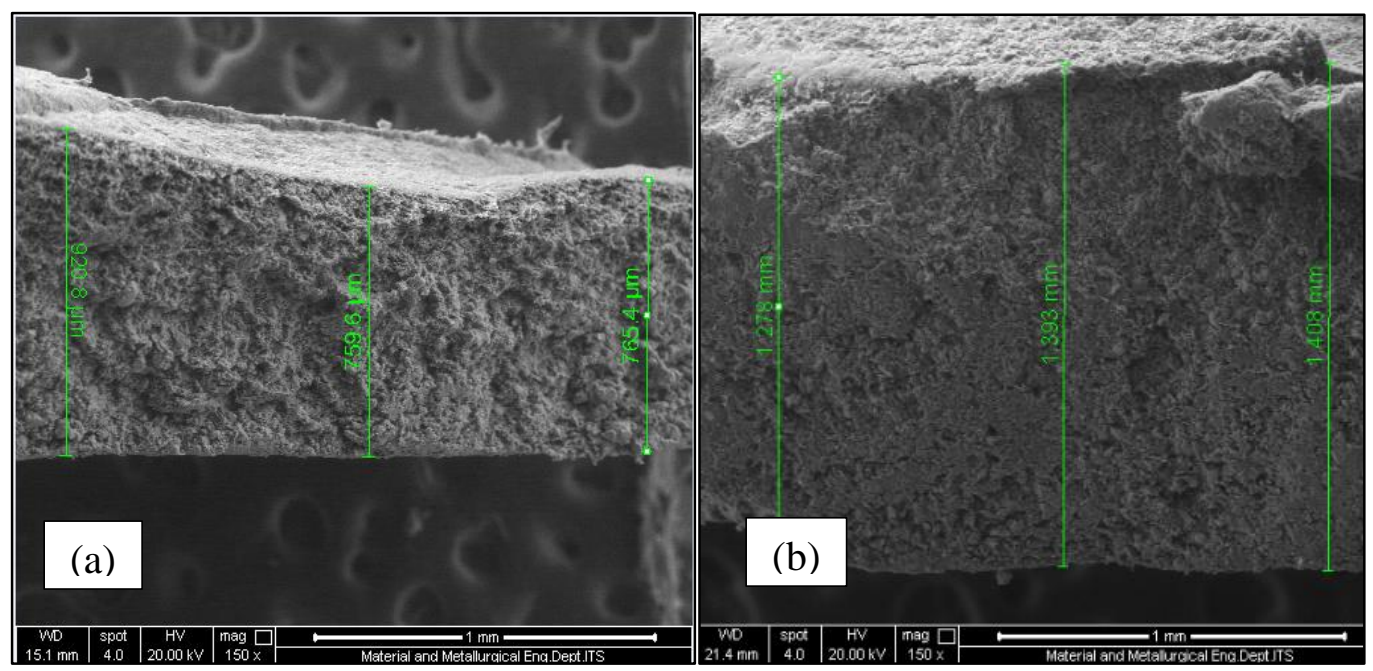

Gambar 3. Hasil Foto SEM tampak Samping (a) Sebelum (b) Sesudah

Gambar 3 (a) menunjukkan struktur morfologi membran tampak samping sebelum digunakan running. Membran memiliki ketebalan yang tidak sama, hal ini dimungkinkan karena saat pencetakan membran tidak dilakukan pemadatan. Ukuran ketebalan membran yang dapat teridentifikasi berdasarkan hasil SEM Gambar 3 (a) $\pm 0,7-1 \mathrm{~mm}$.
Gambar 3 (b) menunjukkan struktur morfologi membran tampak samping setelah digunakan running. Membran yang telah digunakan running memiliki ketebalan yang lebih besar jika dibandingkan membran awal. Hasil SEM Gambar 3 (b) menunjukkan ketebalan membran yang dapat teridentifikasi $\pm 1,2-1,5 \mathrm{~mm}$. Ketebalan membran yang lebih besar ini disebabkan karena adanya foulant atau partikel 
padatan yang tidak dapat tersaring oleh membran, menumpuk sehingga membentuk cake pada membran.Analisa EDX

Energy Dispersive X-ray (EDX) merupakan alat yang dapat digunakan untuk mengetahui komposisi mineral dalam zeolit seperti $\mathrm{Si}, \mathrm{Ti}, \mathrm{Al}$, $\mathrm{Fe}, \mathrm{Mn}, \mathrm{Mg}, \mathrm{Ca}, \mathrm{Na}, \mathrm{K}, \mathrm{P}$. Alat ini bekerja dengan cara menembakkan sinar berenergi tinggi seperti elektron, proton, atau $x$-ray pada sampel. Kemudian energi tersebut akan dilanjutkan ke alat penerima untuk selanjutnya diterjemahkan dalam bentuk puncak-puncak yang menunjukkan macam-macam mineral yang ada dalam sampel. Keunggulan alat ini yaitu tingkat kesalahan yang kecil karena menggunakan elektron untuk mengetahui komposisi sampel. Selain itu waktu analisa yang cepat mempermudah memperoleh hasil analisa.

Komposisi mineral dalam membran zeolit-silika yang tertangkap dalam analisa EDX diantaranya C, N, O, Si, Al, Cl, I, Fe, Zn, Na, Mg, P, S, Ca yang ada pada membran. Hasil analisa EDX yang ditunjukkan dari nilai prosentase komposisi tiap unsur pada membran zeolit-silika dapat dilihat pada Tabel 1. Analisa EDX dilakukan pada saat sebelum dan sesudah proses running.

Tabel 1. Hasil Analisa EDX Membran ZeolitSilika

\begin{tabular}{crrrr}
\hline \multirow{2}{*}{ Unsur } & \multicolumn{2}{c}{ Sebelum } & \multicolumn{2}{c}{ Sesudah } \\
\cline { 2 - 5 } Wt\% & At\% & Wt\% & \multicolumn{1}{c}{ At\% } \\
\hline CK & 43,81 & 56,28 & 38,73 & 51,4 \\
OK & 34,45 & 33,22 & 35,28 & 35,15 \\
ZnL & - & - & 0,63 & 0,15 \\
NaK & - & - & 0,48 & 0,33 \\
MgK & - & - & 2,11 & 1,38 \\
AlK & 2,08 & 1,19 & 3,95 & 2,33 \\
SiK & 13,26 & 7,28 & 11,76 & 6,67 \\
PK & - & - & 0,62 & 0,32 \\
SK & - & - & 0,63 & 0,31 \\
ClK & 1,63 & 0,71 & 2 & 0,9 \\
InL & 3,62 & 0,49 & 1,23 & 0,17 \\
CaK & - & - & 1,28 & 0,51 \\
FeK & 0,52 & 0,14 & 1,3 & 0,37 \\
NK & 0,63 & 0,69 & - & - \\
Matrix & Correction & ZAF & Correction & ZAF \\
\hline \multicolumn{5}{r}{} \\
\hline
\end{tabular}

Tabel 1 menunjukkan beberapa unsur dalam membran yang terlihat melalui analisa EDX sebelum digunakan running hanya $\mathrm{C}, \mathrm{O}, \mathrm{Al}, \mathrm{Si}$, $\mathrm{Cl}$, In, Fe, dan $\mathrm{N}$, sedangkan setelah digunakan running variasi unsur bertambah diantaranya $\mathrm{C}$, $\mathrm{O}, \mathrm{Zn}, \mathrm{Na}, \mathrm{Mg}, \mathrm{Al}, \mathrm{Si}, \mathrm{P}, \mathrm{S}, \mathrm{Cl}, \mathrm{In}, \mathrm{Ca}, \mathrm{Fe}$, dan N. Beberapa unsur dalam membran sebelum digunakan running merupakan unsur-unsur asli yang terkandung dalam bahan utama dan bahan pendukung pembuatan membran, sedangkan beberapa unsur sesudah digunakan running berasal dari foulant/polutan dari air limbah yang tidak dapat difilter oleh membran.

Bahan utama membran yaitu zeolit dan silika, sedangkan bahan pendukung membran diantaranya PEG, PVA, $\mathrm{HCl}, \mathrm{NH}_{4} \mathrm{Cl}$, dan Isopropil alkohol (IPA). Bahan utama membran memiliki unsur diantaranya $\mathrm{Si}, \mathrm{Al}$, dan $\mathrm{O}$, sedangkan bahan pendukung membran diantaranya mengandung $\mathrm{C}, \mathrm{O}, \mathrm{Cl}, \mathrm{In}, \mathrm{Fe}$, dan $\mathrm{N}$. Foulant/polutan dari air limbah yang tidak dapat difilter oleh membran berasal dari limbah laundry. Limbah laundry mengandung detergen dan kotoran-kotoran yang tertempel di pakaian. Kandungan bahan aktif detergen diantaranya natrium alkilbenzena sulfonate, natrium fosfat, natrium karbonat, dll.

Hasil analisa menunjukkan terjadi perubahan persen massa untuk $\mathrm{Si}$ dan Al. Si mengalami perubahan massa dari $13,26 \%$ menjadi $11,76 \%$ sedangkan Al dari 02,08\% menjadi 03,95\%. Penurunan prosentase nilai $\mathrm{Si}$ pada membran disebabkan saat uji EDX luas permukaan membran yang dianalisa hanya pada satu titik dan ini tidak cukup representatif untuk dijadikan sebagai ukuran bahwa prosentase $\mathrm{Si}$ pada membran menurun. Seharusnya pengukuran EDX dilakukan menyebar di beberapa titik pada membran.

Perubahan juga terjadi pada perbandingan prosentase Si dengan Al membran sebelum dan sesudah running yaitu dari 6,38 menjadi 2,98. Semakin kecil perbandingan Si dengan Al maka daya penukar ion dari zeolit akan semakin besar. Literatur tersebut berbanding lurus dengan hasil analisa nilai rejeksi BOD, COD, dan TSS yang cenderung meningkat. 
Berdasarkan hasil analisa EDX diketahui jenis membran zeolit-silika merupakan jenis membran zeolit dengan Si sedang, dimana zeolit jenis ini mempunyai perbandingan kadar Si/Al antara 510. Zeolit dengan Si sedang memiliki permukaan yang mempunyai selektivitas tinggi terhadap air dan molekul polar yang lain.

\section{Hasil Uji Kuat Tarik Membran}

Elastisitas dan ketahanan tarik membran zeolit silika ditentukan melalui uji tarik. Uji tarik mengukur besarnya gaya yang diperlukan untuk membuat membran zeolit - silika terputus. Karakterisasi sifat mekanik (kuat tarik) perlu dilakukan untuk mengetahui kekuatan membran terhadap gaya yang berasal dari luar, yang dapat merusak membran. Kekuatan tarik membran zeolit - silika dapat dilihat dari nilai Load yaitu nilai kuat tegang membran pada saat putus dan Stroke yaitu kekuatan regangan pada saat putus yang dimiliki oleh membran zeolit - silika. Perhitungan kuat tarik membran menggunakan rumus :

$$
\mathrm{E}=\frac{\tau}{e}
$$

Dengan : $\tau=$ tegangan $\left(\mathrm{N} / \mathrm{m}^{2}\right)$

$$
e=\text { regangan }
$$

nilai tegangan dan regangan didapatkan dari rumus :

$$
\begin{gathered}
\tau=\frac{F}{A} \\
e=\frac{\Delta L}{L O}
\end{gathered}
$$

Dengan: $\mathrm{F}=$ Gaya $(\mathrm{N})$

$$
\begin{aligned}
& A \quad=\text { luas penampang }\left(\mathrm{m}^{2}\right) \\
& \Delta \mathrm{L} \quad \text { = pertambahan panjang }(\mathrm{m}) \\
& \text { Lo } \quad=\text { panjang awal membrane }(\mathrm{m})
\end{aligned}
$$

Berdasarkan hasil uji tarik membran zeolit silika sifat mekanik membran diperoleh 0,85 $\mathrm{kgf} / \mathrm{cm}^{2}$ untuk nilai tegangan, 0,59 untuk nilai regangan, dan untuk nilai modulus young sebesar $0,141 \mathrm{~N} / \mathrm{mm}^{2}$. Sifat mekanik dari membran zeolit -silika jika dibandingkan dengan membran jenis lain dapat dilihat pada Tabel 2.

Tabel 1 Sifat Mekanik Beberapa Membran

\begin{tabular}{clr}
\hline No & Jenis Membran & $\begin{array}{c}\text { Modulus Elastisitas } \\
\left(\mathrm{N} / \mathrm{mm}^{2}\right)\end{array}$ \\
\hline 1. & Zeolit A & 50,7 \\
2. & Zeolit-Silika & 0,1 \\
\hline
\end{tabular}

Sumber : (1) Wafiroh, dkk. 2014

(2) Afifah dan Damayanti, 2015

Berdasarkan hasil analisa yang dapat disimpulkan, membran zeolit - silika memiliki elastisitas yang kecil jika dibandingkan dengan membran jenis lain. Untuk menambah tingkat elastisitas membran zeolit - silika, perlu dilakukan penelitian lebih lanjut dengan menambahkan material tertentu saat proses pembuatan membran.

\section{KESIMPULAN}

Variasi penambahan silika dan kecepatan sentrifugasi terbaik untuk pembuatan membran zeolit-silika yaitu membran dengan variasi penambahan silika $1,5 \%$ dan kecepatan sentrifugasi $600 \mathrm{rpm}$. Variasi konsentrasi air limbah terbaik yang dapat direjeksi oleh membran tersebut adalah variasi kosenrasi air limbah $100 \%$. Nilai fluks tertinggi pada variasi terbaik dari penelitian filtrasi limbah laundry dengan membran zeolit-silika untuk menurunkan COD sebesar 54,73 L/m².jam. Nilai rejeksi COD tertinggi pada variasi terbaik dari penelitian filtrasi limbah laundry dengan membran zeolitsilika untuk menurunkan COD sebesar $91,26 \%$.

\section{DAFTAR PUSTAKA}

Afifah, A.S. dan Damayanti, A. (2015). Filtrasi Limbah Laundry dengan Membran Zeolit-Silika Untuk Menurunkan BOD, COD, dan TSS. Institut Teknologi Sepuluh November. Surabaya.

Aprilia, N.I., Sumarni, W., Susatyo, E.B. (2012). Sintesis Membran Padat Silika Abu Sekam Padi dan Aplikasinya Untuk Dekolorisasi Rhodamin B pada Limbah Cair. Indonesian Journal Of Chemical Science, 1(2) 
Aufiyah, dan Damayanti, A. (2013). Pengolahan Limbah Laundry Menggunakan Membran Nanofiltrasi Aliran Cross Flow untuk Menurunkan Kekeruhan dan Fosfat. Institut Teknologi Sepuluh November. Surabaya. Jurnal Teknik POMITS. 2. 2

Barleany, D.R., Rudi, H., dan Santoso., (2011) ,Pengaruh Komposisi Montmorrilonite Pada Pembuatan PolipropilenNanokomposit, Proseding Seminar Nasional Teknik Kimia"Kejuangan",1-6

Citra, S dan Damayanti, A. (2012). Pembuatan sabut kepala sebagai bahan baku pembuatan membran untuk desalinasi air laut. Surabaya : Jurusan Teknik Lingkungan

Lin, J.L., J.R. Pan., dan C. Huang. (2013). Enhanced Particle Destabilization And Aggregation By Flash-mixing Coagulation For Drinking Water Treatment. Journal Separation and Purification Technology. Institute of environmental Engineering, National Chiao Tung University. Taiwan.

Maharani, R.S dan Damayanti, A. (2013). Pengolahan Limbah Cair Rumah Makan Menggunakan Membran Nanofiltrasi Silika Aliran Cross Flow untuk Menurunkan Fosfat dan Amonium. Jurnal Teknik POMITS. 2. 2.

Nasir, S., Budi, T., Silviaty, I. (2012). Laundry Wastewater Treatment Process Using Silica Activated Carbon and Ceramic Filter. International Journal of Academic Research. 4 (2). 85-89.

Prameswari, T. E.B. Susatyo, A.T. Prasetya (2014). Sintesis Membran Kitosan-Silika Abu Sekam Padi Untuk Dekolorisasi Zat Warna Congo Red. Semarang. Indonesian Journal of Chemical Science.
Jurusan Kimia FMIPA Universitas Negeri Semarang

Pusparini, W.R dan Isyuniarto (2010). Teknologi Pemisahan Zr-Hf Menggunakan Metode Kompleksasi-Membran Nanofiltrasi. Yogyakarta : Pusat Teknologi Akselerator dan Proses Bahan BATAN

Rachmawati, B., Surya, Y., dan Mirwan, M. (2014). Proses Elektrokoagulasi Pengolahan Limbah Laundry. Jurnal Ilmiah Teknik Lingkungan. 6. 1

Rosyadi, I.I., Ahmad, M., dan Budiman, A. (2010). Preparasi dan Karakterisasi Bentonit Termodifikasi Surfaktan Kationik Fatty Imidazolinium. Jurnal Sains dan Teknologi Kimia. Jurusan Pendidikan Kimia. Universitas Pendidikan Indonesia

Setyobudiarso, H. dan Yuwono, E. (2014). Rancang Bangun Alat Penjernih Air Limbah Cair Laundry dengan Menggunakan Media Penyaring Kombinasi Pasir - Arang Aktif. Jurnal Neutrino. 6. 2

Susetyaningsih, R., E. Kismolo, Nurimaniwathy (2010). Reduksi Limbah B3 Cair Menggunakan Zeolit Dan Pasir Silika. Seminar Nasional VI. SDM Teknologi Nuklir. Yogyakarta. ISSN 1978-0176

Umaya, W. dan Karnaningroem, N. (2013). Aerasi dan Biorack Wetland Sebagai Pengolah Limbah Laundry. Institut Teknologi Sepuluh Nopember. Surabaya

Wafiroh, S. A.A. Widati, H. Setyawati, dan G. P. Buono (2014). Synthesis and Characterization Of Hybrid Zeolite, A Chitosan Sulfonated Membrane for Proton Exchange Membrane Fuel Cell (Pemfc). Journal of Chemical and Pharmaceutical Research, 6(9):71-76 